\title{
Detecção de Pseudomonas viridiflava em sementes importadas de couve chinesa (Brassica rapa var. pekinensis)
}

\author{
Karen Wolf Maciel ${ }^{1}$, Irene Maria Gatti Almeida ${ }^{1}$, Harllen Sandro Alves Silva², Lucas Mateus Sivero Rodrigues ${ }^{3}$, Luís \\ Otávio Saggion Beriam ${ }^{1}$
}

${ }^{1}$ Instituto Biológico, Caixa Postal 70, 13001-970 - Campinas, SP; ${ }^{2}$ Embrapa Mandioca e Fruticultura Tropical, $44380-000$ - Cruz das Almas, BA; ${ }^{3}$ FCA/UNESP, Depto.de Produção Vegetal, 18603-970 - Botucatu, SP.

Autor para correspondência: Luís O.S. Berian (e-mail: beriam@biologico.sp.gov.br)

Data de chegada: 24/10/2008. Aceito para publicação em: 21/08/2009.

1624

\section{RESUMO}

Maciel, K.W.; Almeida, I.M.G.; Silva, H.S.A; Rodrigues, L.M.S.; Beriam, L.O.S. Detecção de Pseudomonas viridiflava em sementes importadas de couve chinesa (Brassica rapa var. pekinensis). Summa Phytopathologica, v.36, n.1, p.83-84, 2010.

A ocorrência de Pseudomonas viridiflava é descrita em sementes de couve chinesa (Brassica rapa var. pekinensis) importadas do Japão. Do ponto de vista epidemiológico, a detecção dessa bactéria é de extrema importância. Embora já existam, em nosso país, relatos desse patógeno nas culturas de alface, alho, cebola, cenoura, feijão e mandioca, sua presença em sementes de couve chinesa pode se constituir num risco potencial para outras espécies de brássicas aqui cultivadas.

Palavras-chave adicionais: cdoença bacteriana

\section{ABSTRACT}

Maciel, K.W.; Almeida, I.M.G.; Silva, H.S.A; Rodrigues, L.M.S.; Beriam, L.O.S. Detection of Pseudomonas viridiflava in imported chinese cabbage (Brassica rapa var. pekinensis) seeds. Summa Phytopathologica, v.36, n.1, p.83-84, 2010.

A natural occurrence of Pseudomonas viridiflava in chinese cabbage (Brassica rapa var. pekinensis) imported seeds from Japan is described. From the epidemiological point of view, this is a very important observation since the bacterium could be a source of inoculum for other cultived brassicas in Brazil.

Keywords: bacterial disease.

A couve chinesa (Brassica rapa var. pekinensis) é uma folhosa da família das Brassicaceae, cultivada em várias regiões do Estado de São Paulo, sendo importante fonte de cálcio, potássio, vitaminas A e C e ácido fólico (10). Em 2007, lote de sementes de couve chinesa, procedente do Japão foi analisada quanto a incidência de patógenos bacterianos. Em nosso país já foram descritos como patógenos dessa brássicas as bactérias Pectobacterium carotovorum subsp. carotovorum, Xanthomonas campestris pv. campestris e uma Pseudomonas sp. $(11,12)$.

Para a extração da bactéria, alíquotas de sementes foram pesadas e colocadas em maceração em solução salina esterilizada (na proporção de $60 \mathrm{~g}$ de sementes $/ 100 \mathrm{~mL}$ de salina), durante $16 \mathrm{~h}$ a $8^{\circ} \mathrm{C}$. A suspensão obtida foi centrifugada a $16000 \mathrm{~g} / 3 \mathrm{~min}$ a $20^{\circ} \mathrm{C}$ e o precipitado, ressuspendido em 1/10 do volume inicial com solução salina esterilizada. Alíquotas de $100 \mu \mathrm{L}$ tanto da suspensão original como também da concentrada foram colocados, em triplicata, na superfície de placas de Petri contendo meio de cultura [nutriente agar (9) e/ou B de King (7) contendo 0,004\% de cicloheximida] e espalhados com auxílio de alça de Drigalski. Após 48 h de incubação a $28^{\circ} \mathrm{C}$, foram obtidas colônias de coloração branca, bordos lisos e produtoras de pigmento fluorescente em meio BK, sob luz ultravioleta. Os isolados bacterianos foram positivos para reação de hipersensibilidade em plantas de fumo, indicando tratar-se de bactéria fitopatogênica. Esses isolados foram testados quanto à patogenicidade em plantas de couve chinesa. Para os testes, foram utilizados dois métodos de inoculação: infiltração de suspensão bacteriana $\left(\sim 10^{8} \mathrm{UFC}, \mathrm{mL}^{-1}\right)$ em folhas e aspersão da suspensão bacteriana em folhas previamente feridas com agulha esterilizada. Nas plantas testemunhas, o inóculo foi substituído por água esterilizada. As plantas inoculadas foram mantidas em câmara úmida por 72 horas. Sintomas de manchas necróticas em folhas das plantas inoculadas foram observados 5 a 7 dias após as inoculações (Figura 1). Plantas testemunhas permaneceram sadias. Reisolamentos efetuados resultaram em colônias semelhantes às originais.

Os resultados dos testes de levan, oxidade, podridão em discos de batata, arginina-diidrolase e hipersensibilidade em folhas de fumo (LOPAT - - + + ) (8), bem como os dos testes culturais e fisiológicos (2) possibilitaram identificar os isolados em estudo como Pseudomonas viridiflava (Tabela 1).

De acordo com a literatura, $P$. viridiflava é considerada uma bactéria oportunista, que necessita de condições predisponentes muito favoráveis para causar infecção $(3,4)$.

Essa espécie bacteriana possui ampla distribuição e já foi descrita ocorrendo naturalmente num grande número de hospedeiros, incluindo alfafa (Medicago sativa), feijão (Phaseolus vulgaris), cornichão (Lotus corniculatus), repolho (Brassica oleracea var. capitata), couve-flor (B. oleracea var. botrytis), kiwi (Actinidia chinensis), funcho (Anethum 
Tabela 1. Comparação entre os testes LOPAT de isolados de couve chinesa e outras bactérias fitopatogênicas e fluorescentes, pertencentes ao gênero Pseudomonas ${ }^{1}$

\begin{tabular}{|c|c|c|c|c|c|c|}
\hline TESTES & Pseudomonas & (couve chinesa) & P.cichorii & P. marginalis & P. syringae & P.viridiflava \\
\hline Levan & & - & - & + & + & - \\
\hline Oxidase & & - & + & + & - & - \\
\hline Arginina dihidrolase & & - & - & + & - & - \\
\hline Hipersensibilidade em fumo & & + & + & - & + & + \\
\hline
\end{tabular}

${ }^{1}$ Dados obtidos em Bradbury, 1986 (2) e Lelliott et al., 1966 (8)
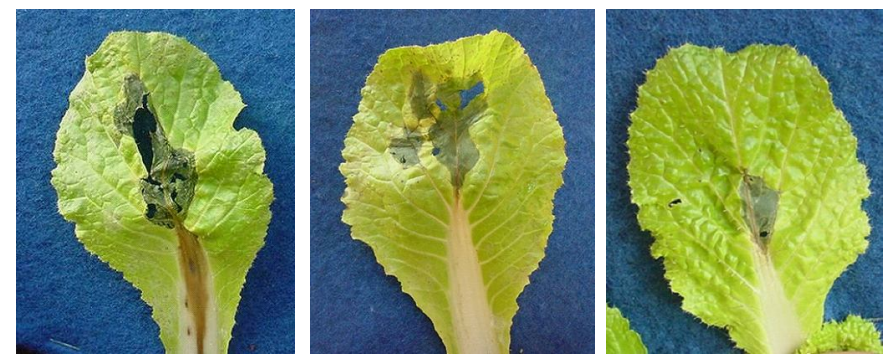

Figura 1. Sintomas observados em folhas de couve chinesa inoculadas com Pseudomonas viridiflava

graveolens), uva (Vitis vinifera), alface (Lactuca sativa), tremoço (Lupinus angustifolius), pastinaga (Pastinaca sativa), maracujá (Passiflora edulis), ervilha (Pisum sativum), pimentão (Capsicum annuum), bico-de-papagaio (Euphorbia pulcherrima), papoula (Papaver somniferum), abóbora (Cucurbita maxima), colza (B. napus var. napus) e tomate (Lycopersicon esculentum) (5). Algumas outras espécies botânicas estão também citadas como hospedeiros por inoculação artificial, como trigo sarraceno (Fagopyrum esculentum), trevo (Trifolium pratense), feijão caupi (Vigna unguiculata), cártamo ou safflower (Carthamus tinctorius), sorgo (Sorghum vulgare), soja (Glycine max) e zínia (Zinnia elegans) (5).

Ainda, em trabalhos sobre a bactéria, agente causal da "estria bacteriana e podridão de bulbos de cebola", Gitaitis et al. $(4,5)$ relataram que não se conhecem resultados em literatura a respeito da sobrevivência de $P$. viridiflava em sementes, mas que a bactéria pode sobreviver como epífita em associação com plantas daninhas. Segundo Goumans \& Chatzaki (6), a ocorrência doenças em diversos hospedeiros, ocasionada por $P$. viridiflava e o reaparecimento dessas doenças em condições de casa-de-vegetação corroboram que essa espécie bacteriana seja um patógeno oportunista

Em nosso país, existem relatos desse patógeno nas culturas de alface, alho, batata, cebola, cenoura, feijão e mandioca $(1,11)$. É importante salientar a relevância dos testes de sanidade de sementes como medida preventiva, evitando a introdução ou reinfestação de áreas sadias. A descrição da bactéria em sementes importadas de couve chinesa se reveste de extrema importância, uma vez que essa espécie bacteriana poderá se constituir em risco potencial para outras brássicas, além de outras espécies de plantas hospedeiras cultivadas em nosso meio. Linhagem bacteriana encontra-se depositada na Coleção de Culturas IBSBF sob n ${ }^{\circ} 2517$.

\section{REFERÊNCIAS BIBLIOGRÁFICAS}

1. Almeida, I.M.G.; Maciel, K.W.; Siqueira, E.S.; Malavolta Júnior, V.A.; Rodrigues Neto, J.; Beriam, L.O.S. Identificação de Pseudomonas viridiflava em sementes de cenoura (Daucus carota) importadas do Japão. Summa Phytopathologica, Botucatu, v.34, suplemento, p.S-106-107.2008.

2. Bradbury, J.F. Guide to plant pathogenic bacteria. Kew: CAB International, 1986. 332p.

3. Gitaitis, R.D.; Baird, R.E.; Beaver, R.W.; Sumner, D.R.; Gay, J.D.; Smittle, D.A. Bacterial blight of sweet onion caused by Pseudomonas viridiflava in Vidalia, Georgia. Plant Disease, St. Paul, v.75, n.11, p.1180-1182, 1991.

4. Gitaitis, R.; Sumner, D.; Gay, D.; Smittle, D.; MacDonald, G.; Maw, B.; Johnson III, W.C.; Tollner, B.; Hung, Y. Bacterial streak and bulb rot of sweet onion: I. A diagnostic medium for the semiselective isolation and enumeration of Pseudomonas viridiflava. Plant Disease, St. Paul, v.81, n.8, p.897-900, 1997.

5. Gitaitis, R.; MacDonald, G.; Torrance, R.; Hartley, R.; Sumner, D.R.; Gay, J.D.; Johnson III, W.C. Bacterial streak and bulb rot of sweet onion: II. Epiphytic survival of Pseudomonas viridiflava in association with multiple weed hosts. Plant Disease, St. Paul, v.82, n.8, p.935-938, 1998.

6. Gomans, D.E.; Chatzaki, A.K. Characterization and host range evalution of Pseudomonas viridiflava from melon, blite, tomato, chrysanthemum and eggplant. European Journal of Plant Pathology, Dordrechet, v..104, n.1, p.181-188.1998

7. King, E.O.; Ward, M.K.; Raney, D.E. Two simple media for the demonstration of pyocyanin and fluorescin. Journal of Laboratory and Clinical Medicine, St. Louis, v.44, p.301307, 1954.

8. Lelliott, R.A.; Billing, E.; Hayward, A.C. A determinative scheme for the fluorescent plant pathogenic Pseudomonads. Journal of Applied Bacteriology, Oxford, v.29, n.3, p.470489, 1966.

9. Levine, M. An introduction to laboratory technique in bacteriology. New York: Mac Millan, 1954. p. 68-79.

10. Lorenz, O.A.; Maynard, D.N. Knotts handbook for vegetable growers. $3^{\text {rd }}$. New York. A Wiley-Interscience Publication, 1988. 456p.

11. Malavolta Jr., V.A.; Beriam, L.O.S.; Almeida, I.M.G.; Rodrigues Neto, J.; Robbs, C.F. Bactérias patogênicas a plantas ornamentais ocorrendo no Brasil: uma atualização. Summa Phytopathologica, Botucatu, v.34, suplemento especial, p.188,2008 .

12. Santos, C.D.G.; Romeiro, R.S.; Oliveira, M.S. Uma nova bacteriose da couve chinesa em Minas Gerais. Fitopatologia brasileira, Lavras, v. 12, n. 2, p.140,1987. 